\title{
A OUTRA MARGEM: A QUESTÃO DA LUSOFONIA E DA ORALIDADE EM LUANDINO VIEIRA E MIA COUTO
}

Aulus Mandagará Martins*

RESUMO: O objetivo deste artigo é refletir sobre o problema da língua portuguesa na obra de Luandino Vieira e Mia Couto, sobretudo no que diz respeito à presença da oralidade. A partir das posições da Alfredo Margarido e Eduardo Lourenço acerca da lusofonia e de seus desdobramentos, isto é, o uso simbólico político da língua portuguesa fora da Metrópole, destacaremos que o projeto literário dos escritores angolano e moçambicano divergem quanto às estratégias de incorporação da oralidade em seus textos ficcionais.

PALAVRAS-CHAVE: lusofonia; oralidade; Luandino Vieira; Mia Couto
* aulus.mm@gmail.com

Doutor em Letras. Professor da Universidade Federal de Pelotas.
ABSTRACT: The objective of this paper is to reflect upon the problem related to the Portuguese language in Luandino Vieira and Mia Couto literary productions, especially concerning the presence of orality on those works. From Alfredo Margarido's and Eduardo Lourenço's considerations on Lusophony and its varieties, that is, the symbolic and political use of the Portuguese language away from metropole, we are going to highlight that the literary project of the Angolan writer differs from the Mozambican author due to the disparate incorporation of orality strategies within their fictional texts.

KEYWORDS: lusophony; orality; Luandino Vieira; Mia Couto. 


\section{LUGAR DE ONDE SE FALA, LUGAR DE QUE SE FALA}

É preciso lembrar, antes de tudo, o óbvio: no contexto brasileiro, falar da literatura africana de língua portuguesa é falar de um lugar sobre outro lugar; desta forma, o exercício crítico não deve esquecer que nosso olhar, em que pese todos os laços de parentesco, será sempre um olhar estrangeiro, que, como tal, deve rejeitar, a priori, formulações que traem, mesmo inconscientemente, uma percepção do outro contaminada por paradigmas culturais ou políticos que lhe são alheios ou estranhos. A ressalva é importante para desfazer pelo menos um equívoco ainda presente nos estudos de literatura africana, cuja investigação não pode se confundir com uma espécie de compensação acadêmica ao recalque da cultura africana no cenário da intelectualidade brasileira. É certo que o legado africano foi apagado e que deve ser recuperado para que possamos entender os processos de formação de nossa sociedade e sua atual dinâmica. Nessa perspectiva, pensando no papel da crítica literária, tão importante quanto o questionamento dos pressupostos do cânone e os procedimentos de representação do outro, ou, ainda, a valorização da cultura africana ou afro-brasileira, é a problematização do texto literário entendido como um discurso esteticamente elaborado, bem como sua relação com outros códigos ou discursos, que se coloca no centro do debate. Por outras palavras, o estudo da literatura africana de língua portuguesa deve destacar as soluções estéticas e discursivas presentes nos sistemas literários angolanos, moçambicanos etc., com as quais os escritores desses países pensam e representam suas questões culturais, políticas, sociais, e não apenas encontrar nesses textos questões que dizem mais respeito a nós do que a eles.

Voltando, pois, à problemática dos lugares de enunciação, gostaríamos de propor que, entre o lugar de onde se fala o lugar de que se fala, podemos inserir um terceiro espaço, lugar em que esses lugares se encontram e se tencionam: a lusofonia.

A lusofonia, por certo, não é por certo um termo inocente. De acordo com a definição dicionarizada, designa o conjunto de países que têm o português como língua oficial ou dominante. A polêmica que se arma em torno da noção de lusofonia diz respeito, sobretudo, a dois aspectos, de acordo com Eduardo Lourenço ${ }^{1}$. O primeiro aponta para o contexto histórico-social em que a língua portuguesa expandiu-se pelo mundo e às relações de poder decorrentes dessa expansão; o segundo, ao caráter polissêmico e difuso da palavra, que é associada indistintamente a ideologias políticas, relacões culturais, trânsitos supranacionais, questões linguísticas e identitárias. De qualquer forma, em ambos os casos, a noção de lusofonia decorre de uma questão linguística, pois, se existe a lusofonia é porque existe a língua portuguesa $-e$ mesmo nesse aspecto tão óbvio a polêmica se instala, uma
1. Cf. LOURENÇO, Eduardo. $A$ nau de lcaro e imagem e miragem da lusofonia. São Paulo: Companhia das Letras, 2001.

\begin{tabular}{|c|c|c|c|c|c|}
\hline EM TESE & BELO HORIZONTE & v. 22 & SET.-DEZ. 2016 & MARTINS. A outra margem: a questão da lusofonia e da oralidade [...] & Р. 284-293 \\
\hline
\end{tabular}


2. MARGARIDO. A lusofonia e os lusófonos, p. 76

3. LOURENÇO. A nau de Ícaro, p. 189 vez que se trata de verificar a extensão e o peso da língua na constituição da lusofonia: para alguns, a língua portuguesa é o seu principal elemento, dentre tantos, e, para outros, o único possível.

Alfredo Margarido, em A lusofonia e os lusófonos, condena o uso que determinados setores da sociedade portuguesa fazem da lusofonia, transformando-a em um instrumento ideológico de contornos neocolonialistas, com indisfarçada intenção de restaurar o Império perdido mediante uma reivindicação de propriedade linguística. Desse modo, ainda na percepção de Margarido, a noção de lusofonia, ao propor uma pátria linguística supranacional, atualiza a velha hierarquia imperialista, substituindo o projeto civilizatório do colonialismo por um projeto agora centrado na língua, ainda hegemônico, uma vez que tende a considerar a existência do "Outro" apenas após o encontro com o explorador português, ou melhor, com a língua portuguesa ${ }^{2}$. A noção de lusofonia, que procura solucionar as inúmeras contradições do passado imperialista, na verdade aprofunda-as, trazendo à tona a falência do projeto colonialista e o paradoxal desejo de recuperar, simbólica e talvez politicamente, os "espaços imperiais”, como afirma Eduardo Lourenço ${ }^{3}$. Nessa perspectiva, a valorização ou até mesmo hipervalorizarão da língua portuguesa, hoje, evidencia a ausência, no passado (estamos pensado evidentemente na África), de um "projeto pedagógico" (ainda segundo Lourenço) ${ }^{4}$ de divulgação da língua, cujo uso restringia-se aos colonos portugueses. Alfredo Margarido interpreta essa lacuna a partir das convicções racistas do colonizador português, para quem o africano, inferior intelectualmente, era incapaz de aprender corretamente a língua portuguesa. Para a mentalidade colonialista portuguesa, a ignorância da língua não se constituía em entrave ao projeto imperialista, uma vez que (e retomamos Margarido) o africano poderia muito bem trabalhar para os colonos, "mesmo

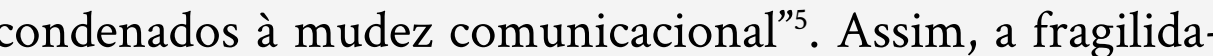
de da língua portuguesa verificada nas ex-colônias africanas não deixa de ser um atestado da incompetência portuguesa na execução de um projeto muito mais grandioso do que capacidade lusitana, naquilo que Boaventura de Sousa Santos chama de colonialismo periférico ${ }^{6}$.

Dessa maneira, o conceito de lusofonia, que se apresenta com as vestes de um pensamento moderno, carrega a herança de uma "ideologia-estrume", nas palavras de Margarido" A partir de um pensamento português conservador, a lusofonia talvez seja outra palavra o luso-tropicalismo, formulado pelo brasileiro Gilberto Freyre ao longo de sua extensa obra, principalmente em Casa Grande e Senzala (1933). Prova disso é a uso mais ou menos corrente da expressão "pós-luso-tropical" para designar a lusofonia, utilizada tanto para exaltá-la quanto para criticá-la.
4. LOURENÇO. A nau de Icaro, p. 187.

MARGARIDO. $A$ lusofonia e os lusófonos, p. 50.

6. SANTOS. A gramática do tempo pp. 203ss.

7. MARGARIDO. A lusofonia e os lusófonos, p. 57 
Como se sabe, o luso-tropicalismo no pensamento de Gilberto Freyre procura dar conta do processo de miscigenação racial e hibridismo cultural verificado na sociedade brasileira, descrito em termos de generosidade do homem branco para com o homem negro. Para Freyre, a miscigenação racial existe por efeito de uma aclimatação do português nas colônias, que soube abdicar de sua posição superior para interagir com outras raças e culturas. Nesse sentido, o luso-tropicalismo suprime as contradições ideológicas presentes na miscigenação e no hibridismo, resolvendo a questão de forma caseira, digamos, uma vez que a casa grande e a senzala encontram-se na cozinha ou na cama na mulher negra, sem elidir naturalmente os papéis sociais dos agentes envolvidos em tão produtivo conluio. Não é uma simples coincidência, portanto, que o luso-tropicalismo tenha se tornado a ideologia oficial do Estado Novo salazarista para as questões do ultramar. Discurso que, registre-se de passagem, é minando em seu cerne em textos literários (escritos do "português de Portugal") como Os cus de Judas de Lobo Antunes e A costa dos murmúrios de Lidia Jorge. Este último, ao narrar as experiências de uma jovem portuguesa que acompanha o marido militar na Guerra Colonial em Moçambique, inviabiliza a ideologia salazarista que previa às mulheres, além do pedido de sacrificarem seus filhos e maridos pela Pátria, uma "nobre missão", que se desdobrava em dois aspectos: uma missão familiar (acompanhar os maridos à guerra para manter a célula da família lusitana) e uma civilizadora (a presença da mulher branca na África tinha por escopo "valorizar a mulher negra"). Embora não lutassem nas frentes de batalha, tinham uma posição na retaguarda da guerra, por assim dizer. O Regime salazarista, apelando para o luso-tropicalismo, transformava as mulheres em cúmplices dos maridos, da guerra e, sobretudo, do próprio Regime ${ }^{8}$.

Confundir lusofonia e luso-tropicalismo parece ser, portanto, uma tentativa de bloquear uma acepção mais ampla e profunda dos encontros culturais mediados pela língua portuguesa. Tal confusão explica em parte a desconfiança, ou até mesmo a rejeição do termo lusofonia no contexto africano, cujos países que falam o português apenas recentemente superaram a dominação política.

Em oposição aos matizes neocolonialistas que a lusofonia poderá assumir, é possível vislumbrar no termo um positivo e frutífero espaço simbólico de trocas culturais. Este é sem dúvida o caso de Eduardo Lourenço, em cuja obra ensaística empenha-se na construção de um território lusófono plural em que a língua portuguesa tanto unifica quanto expõe as contradições e conflitos do processo que permitiu sua expansão. O autor de $A$ nau de Ícaro observa que a lusofonia não tem e nem poderia ter o mesmo significado em todos os pontos cardeais desse espaço que possui uma língua em comum . Se a língua é a mesma, não se trata de pensá-la como
8. Cf. RIBEIRO, Margarida Calafate. Africa no feminino: As mulheres portuguesas e a Guerra Colonial. Porto: Edições Afrontamento 2007

9. LOURENCCO. A nau de Ícaro, p. 179
EM TESE
BELO HORIZONTE
v. 22
N. 3
SET.-DEZ. 2016
MARTINS. A outra margem: a questão da lusofonia e da oralidade [...]
p. $284-293$ 
10. LOURENÇO. A nau de Ícaro, p. 121

11. LOURENÇO. A nau de Ícaro, p. 182

12. LOURENÇO. A nau de Ícaro, p. 111

13. LOURENÇO. A nau de Ícaro, p. 183

14. LOURENÇO. A nau de Ícaro, p. 176 "um fator contingente de comunicação entre os homens, mas [como] a expressão de sua diferença" ${ }^{\prime 10}$. Deste modo, lusofonia não se confunde com portugalidade: embora Portugal seja o "espaço matricial da língua portuguesa", não se pode atribuir a essa centralidade "na esfera lusófona outra dimensão que não seja essa de essência genealógica" ${ }^{11}$. Em que pese, de fato, a permanência de uma mentalidade imperialista no imaginário português, a lusofonia deve ser pensada como uma "galáxia"12, uma "tapeçaria de diversa consistência e trama" ${ }^{13}$, como, enfim, um "continente imaterial disperso pelos vários continentes" ${ }^{\prime 14}$ onde se fala o português.

O pensamento de Eduardo Lourenço parece fornecer um importante referencial crítico para pensar a relação entre as literaturas de língua portuguesa. Entendida como o espaço simbólico em que a "matriz linguística" não ocupa uma posição hegemônica, a noção de lusofonia só se tornou possíve com a independência política dos cinco países africanos que têm o português como língua oficial. A entrada dos PALOP (como assim foram denominados os Países Africanos de Língua Oficial Portuguesa, pasteurizados nessa sigla um tanto suspeita) nesse cenário evidenciou a necessidade de um novo (ou verdadeiramente primeiro) mapa da lusofonia cujos territórios, a partir de então, devem ser redesenhados a fim de que as literaturas daqueles países encontrem o lugar e o modo de estar que lhes cabe no "continente imaterial", ou, dito de outra forma, o lugar de onde ecoa a língua portuguesa, que não é mais (ou apenas) aquela do "espaço matricial" e sim aquela que, por expressar a diferença, lhes garante um lugar na "galáxia" lusófona.

O PROBLEMA DA LÍNGUA: UM “TROFÉU DE GUERRA”

O problema da língua sempre se impôs aos escritores dos países colonizados, uma vez que se escreve com ou na língua do colonizador. O surgimento de uma nova consciência política, a partir da qual se reivindica a libertação do sistema colonial, tem como consequência uma também nova consciência linguística, pois, a língua, além de alheia, pertence ao inimigo e, portanto, veicula o conjunto de valores contra os quais se luta. Os estudos pós-coloniais apontam para uma relação dialética do escritor com a língua, diante do projeto político de se "escrever a nação", de acordo com os postulados de Bhabha ${ }^{15}$. Se de um lado é preciso rejeitar os valore do colonizador, incluindo a língua, por outro lado, não há como se desvencilhar da herança da colonização. A questão, nesse caso, não seria tanto ab-rogar a língua do colonizador mas assimilá-la, usá-la em proveito próprio, transformando o instrumento de opressão em instrumento de libertação e afirmação cultural. O que se postula então é tanto a desocupação do território pelo inimigo quanto a apropriação de sua língua. Nesse sentido, parece ser emblemática a posição de Luandino Vieira. A língua portuguesa, afirmou o escritor,
15. Cf. BHABHA, Homi K. O local da cultura. Trad. AVILA, M; REIS, E. GOMÇA.VES, G. Belo
EM TESE
BELO HORIZONTE
SET.-DEZ. 2016 
logo após a libertação de Angola, é um "troféu de guerra"16. $\mathrm{Na}$ imagem bélica evidencia-se a vitória sobre o inimigo e a consequente conquista de um valioso espólio, que as guerras de um modo geral colocam em jogo. É possível perceber ainda na frase de Luandino certa ironia, uma vez que a vitória é proclamada justamente na língua do inimigo, agora um "troféu", para que sobre esta conquista não paire nenhuma dúvida.

Contudo, interessa-nos verificar, no caso das literaturas africanas de língua portuguesa, de que forma essa dialética da ab-rogação e assimilação da língua, ultrapassando os limites de uma mera posição política, historicamente datada, é transposta para o plano da linguagem literária. Isso significa dizer que o gesto de apropriação da língua portuguesa depende menos de uma consciência linguística, no sentido da língua como instrumento de comunicação entre os homens, e mais de uma consciência estética. Assim, a literatura torna-se o espaço privilegiado de um processo de assimilação linguística, sugerindo que a posse da língua é legitimada pelo uso estético que dela se faz.

\section{TRANSCRIÇÃO, RECRIAÇÃO, INVENÇÃO}

É nessa direção que se desenvolve o projeto literário de Luandino Vieira, em obras como Luuanda (1963), Nós, os do Makulusu (1974) e Lourentinho, Dona Antónia de Sousa Neto
$\mathcal{E} \mathrm{eu}$ (1981), sobretudo a partir de uma estratégia linguística que pode ser descrita pela incorporação da língua falada nos musseques ao registro escrito da língua portuguesa. Assim, a língua oficial da metrópole é, justamente, um "troféu", que ostenta, não apenas a vitória militar ou política, mas principalmente a conquista de um bem imaterial e, portanto, simbólico, a língua portuguesa, agora não mais dos portugueses, mas também dos angolanos, uma vez que "contaminada" pelo léxico e estruturas sintáticas oriundas das línguas nativas. Não se trata, evidentemente, de uma mera transcrição da oralidade, da fala das ruas da gente humilde, mas de uma criação poética, resultante da fusão e combinação da língua portuguesa oficial e das línguas nativas. Muito mais do que dar voz aos habitantes dos musseques, postos à margem do sistema, simbólica e geograficamente, Luandino, utilizando-se do código escrito e da linguagem literária, traz para o sistema da língua portuguesa oficial uma língua banida desse mesmo sistema, sugerindo que é por meio desta língua portuguesa, "nova" "outra", que irá se consolidar a língua portuguesa africana e, ainda, pensando na esfera política, a emancipação do sistema colonial, cuja evidência é a posse de uma língua capaz de "escrever a nação" emancipada. É interessante observar que se trata, pois, de uma língua que já nasce em sofisticado plano linguístico, vale dizer, no plano literário.

Não é à toa, portanto, que Luandino Vieira vá buscar em João Guimarães Rosa o modelo para essa tomada de 
17. Cf. SANTILLI, Maria Aparecida. João Guimarāes Rosa e José CHAVES, Rita: MACÊDO Tania: VECCHIA Rejane (org). $A$ kinda a misanga. Encontros brasileiros com a literatura angolana. São Paulo: Cultura Acadêmica; Luanda: Editorial Nzila, 2007.

18. VIEIRA. Luuanda, p. 50 consciência linguística e estética, como muitos estudiosos ja observaram, dentre os quais Santilli ${ }^{17}$, para citar apenas um exemplo. O que o escritor angolano aprende com o mineiro não é tanto a possibilidade de trabalhar o vocábulo através de neologismos, mas sobretudo de criar uma linguagem outra, que não surge do vazio, e sim do encontro e da mistura de falares que não ocupam a mesma posição no sistema linguístico. Assim como Guimarães Rosa dignifica, pelo registro literário, a fala desprestigiada do sertanejo mineiro, não pela transcrição dessa fala, mas por sua recriação poética, erudita Luandino Viera recria a fala do angolano pobre habitante do musseque, elevando-a ao patamar de prestígio da língua portuguesa oficial. Vejamos uma passagem do conto "Estória do ladrão e do papagaio" de Luuanda:

Nem uazekele kié-uazeka kiambote, nem nada, era só assim a outra maneira civilizada como ele dizia, mas também depois ficava na boa conversa de patrícios e, então, aí o quimbundo já podia se assentar no meio de todas as palavras, ele até queria, porque para falar bem-bem português não podia, o exame da terceira é que estava lhe tirar agora e por isso não aceitava falar um português de toda a gente, só queria falar o mais superior. E na hora de adiantar escolher as duas pessoas, ou quatro tanto faz, para saírem com os baldes de creolina e pano lavar as prisões dos brancos, essa simpatia era muito precisa, para escapar... ${ }^{18}$
Este trecho poderia servir a inúmeros propósitos, tais como ilustrar a pluralidade linguística, o entrecruzamento de registros ou, ainda, a ideologia do colonizador perpetrada pelo colonizado, a partir da qual o idioma português é estratificado na polarização de um "de toda a gente" e de um outro "o mais superior”. O que gostaríamos de assinalar é a dicção do narrador que, ao narrar as "estórias" da gente do musseque, opta pela oralidade, cujo efeito é o nivelamento entre a fala das personagens, fala supostamente estropiada face à língua do colonizador, e a fala do narrador, que, neste caso, abdica tanto de seu ponto de vista privilegiado e distante da matéria narrada quanto da língua a "mais superior" (posto que deste narrador se esperaria a adesão ao registro culto e oficial da língua) para, ele próprio, participar, com sua língua (quer dizer: a língua do musseque), do universo narrado. Desse modo, o olhar do narrador não capta apenas as estórias do musseque, seus costumes e hábitos linguísticos exóticos, mas narra a partir de uma visão de mundo da qual se integra. A voz que narra não e, portanto, uma voz estranha e estrangeira do mundo narrado. É, por assim dizer, uma voz "desentranhada" (para utilizarmos uma metáfora bandeiriana) dessa realidade, única voz, registre-se, possível de dar substância a esse mundo. Isso dito, a oralidade em Luandino Vieira é um projeto de ocupação política da língua portuguesa, que não se restringe, todavia, a uma demanda meramente política de legitimar os usos africanos da língua portuguesa, mas que alcança sua potência 
19. LOURENÇO. A nau de Ícaro, p. 196

20. MATA. A alquimia da língua portuguesa nos portos da expansão em Moçambique, com literários em romance de Mí Couto. Couto. na expressão poética que se constrói na língua que, como bem imaterial, é, nas palavras de Eduardo Lourenço, "miticamente comum por ser de todos e de ninguém"19.

\section{ORALIDADE "ARTESANAL"}

A obra do moçambicano Mia Couto parece dar continuidade ao projeto literário de Luandino Vieira, mediante ainda a lição de Guimarães Rosa. Entretanto, a estratégia de Mia Couto já não contempla, pelo menos em posição de destaque, a incorporação de léxico e estruturas das línguas nativas. Não se pode afirmar, portanto, que o escritor moçambicano recrie a língua portuguesa através da combinação de diferentes falares. O que Mia Couto faz, em obras como Terra sonâmbula (1992), Estórias abensonhadas (1994), A varanda do frangipani (1996) e O último voo do flamingo (2000]), lembra mais um outro procedimento estilístico bastante forte em Guimarães Rosa, qual seja, o trato poético da palavra, que resulta na criação de neologismos. Muitos estudos já verificaram essa familiaridade, demonstrando que ambos os escritores se utilizam dos mesmos procedimentos linguísticos de formação de palavras (MATA, 1998; VALENTE, $2007)^{20}$. Aliás, registre-se de passem, um ou outro crítico já observou o acúmulo de neologismos na prosa de Mia Couto, o que promoveria um enfraquecimento desse recurso, por sua previsibilidade. Contudo, é preciso entender a dimensão desse traço estilístico em sua obra.
O parágrafo de abertura do conto "O poente da bandeira" de Estórias abensonhadas ilustra essa marca linguística bem característica da prosa de Mia Couto:

Aurorava. O sol dava as cinco. As sombras, neblinubladas, iam espertando na ensonação geral. No topo das árvores, frutificavam os pássaros. Toda madrugada confirma: nada, neste mundo, acontece num súbito. A claridade já muito espontava, como lagarta luzinhenta roendo o miolo da escuridão. As criaturas se vão recortando sob o fundo da inexistência. Neste tempo uterino o mundo é interino. O céu se vai azulando, permeolhável. Abril: sim, deve ser demasiado abril. Agora, que a aurora já entrou neste escrito, entremos nós no assunto ${ }^{21}$.

A reiteração de neologismos parece apontar para outra estratégia linguística de apropriação do idioma, vala dizer, o desejo de construir, no recorte da língua portuguesa, uma língua própria, uma dicção pessoal, uma voz autoral, não completamente cifrada, posto que resultante de uma maneira peculiar de manipular o vocabulário da língua, que é também a língua do leitor. Nesse sentido, a escrita de Mia Couto pode ser entendida como outro estágio da dialética da ab-rogação assimilação da língua. No contexto histórico em que Mia Couto escreve, entende-se que a língua portuguesa já foi suficientemente ab-rogada e assimilada. Trata-se agora de construir as dicções ou dialetos pessoais dessa língua
21. Cf. COUTO, Mia. Estórias abensonhadas. São Paulo: Cia. das Letras, 2012.
EM TESE
BELO HORIZONTE
v. 22
N. 3
SET.-DEZ. 2016
MARTINS. A outra margem: a questão da lusofonia e da oralidade [...]
p. 284-293 
22. MATA. $A$ alquimia da língua portuguesa nos portos da expansão em Moçambique, com Mia Couto, p. 263.

23. MATA. $A$ alquimia da língua portuguesa nos portos da

Mia Couto, p. 264. Grifos do autora.

24. MATA. $A$ alquimia da língu portuguesa nos portos da expansão em Moçambique, com portuguesa africana, evidenciando, mais uma vez, uma consciência linguística que problematiza constantemente a dimensão estética da linguagem.

Inocência Mata observa que Mia Couto é "o escritor africano em que a reinvenção linguística atinge uma extraordinária artesania sempre aliada a uma reflexão histórica, político-social e ideológica"22. Essa artesania, ainda segundo a autora, remete a uma "nova geografia linguística, uma nova ideologia para pensar e dizer o país"23. Trata-se, pois, de uma espécie de "pseudo-oralidade" 24 , como também é a de Luandino Vieira, uma vez que, em ambos os escritores, a questão não é reproduzir a língua falada, mas conferir-lhe um significado ideológico e poético. No caso de Mia Couto, os neologismos (aurorava, neblinubladas, luzinhenta, permeolhável) configuram um gesto de apropriação da língua em que a língua portuguesa é distendia para uma "nova geografia", esse lugar a partir do qual o narrador, como que ciente de que a língua de "de toda a gente" não daria conta das complexidades his tórica, cultural e linguística da lusofonia, interfere na gramática para expressar novas modalidades de entender e dizer seu país. Essa liberdade de interferir na gramática assinala um gesto essencialmente ideológico, conferindo a todos os falantes igual direito sobre a língua portuguesa. Também um gesto poético porque a palavra nova parece apontar para uma experiência sobre a realidade que só é possível porque foi possível dizê-la de uma nova forma.

\section{A OUTRA MARGEM: GALÁXIA}

Para finalizar, retomamos a imagem de Eduardo Lourenço da lusofonia como uma "galáxia", metáfora pela qual se indica que o espaço da língua portuguesa não se reduz ao "espaço matricial", seu lugar de origem, mas trata-se de um espaço múltiplo, quer dizer, de um "continente imaterial disperso pelos vários continentes" onde se fala o português. E nesse sentido que a oralidade desempenha um papel fundamental na construção dessa "galáxia", pois é pela incorporação ao idioma desses falares outros, dispersos pelo mundo que fala a língua portuguesa, que a que a língua portuguesa é verdadeiramente lusófona, quer dizer, um bem imaterial que pertence a toda comunidade que fala o português. Em um outro contexto, o angolano Ruy Duarte de Carvalho fala que "não há lugar achado sem lugar perdido" 25 . É justamente essa dialética que anima a relação dos escritores africanos com a língua portuguesa - e, por extensão, a comunidade que possui o português como língua oficial. O lugar da lusofonia é o espaço em que a língua é constantemente descoberta e perdida. Se os portugueses nos deixaram este legado, a nós, lusófonos, habitantes desse continente imaterial, significa dizer que eles a perderam um pouco, para achá-la mais adiante, não uma língua perdida ou extraviada de sua origem, mas ainda a língua portuguesa, que nos separa e nos une.
25. Cf. CARVALHO, Ruy Duarte. Hábito da terra. Porto; Luanda: Edições Asa; União dos Escritores Angolanos, 1988.
EM TESE
BELO HORIZONTE
v. 22
N. 3
SET.-DEZ. 2016
MARTINS. A outra margem: a questão da lusofonia e da oralidade [...]
P. 284-293 


\section{REFERÊNCIAS}

BHABHA, Homi K. O local da cultura. Trad. ÁVILA, M; REIS, E.; GONÇALVES, G. Belo Horizonte: UFMG, 2003.

CARVALHO, Ruy Duarte. Hábito da terra. Porto; Luanda: Edições Asa; União dos Escritores Angolanos, 1988.

COUTO, Mia. Estórias abensonhadas. São Paulo: Cia. das Letras, 2012

HAMILTON, Russell G. A literatura dos PALOP e a Teoria PósColonial. Via Atlântica, São Paulo, n.3, pp. 12-22, 1999

LOURENÇO, Eduardo. A nau de Ícaro e imagem e miragem da lusofonia. São Paulo: Companhia das Letras, 2001.

MARGARIDO, Alfredo. A lusofonia e os lusófonos: novos mitos portugueses. Lisboa: Edições Universitárias Lusófonas, 2000.

MATA, Inocência. A alquimia da língua portuguesa nos portos da expansão em Moçambique, com Mia Couto. Scripta, Belo Horizonte, v.1, n..2, pp. 262-268, 1998.

MATA, Inocência. A condição pós-colonial das literaturas africana de língua portuguesa: algumas diferenças e convergências e

muitos lugares-comuns. In: LEÃO, Ângela Vaz (org.). Contatos

e ressonâncias: literaturas africanas de língua portuguesa. Belo Horizonte: PUC Minas, 2003

MATA, Inocência. No fluxo da resistência: A literatura, (ainda) universo da reinvenção da diferença. Gragoatá. Niterói, n.27, pp. 11-31, 2009.
RIBEIRO, Margarida Calafate. Africa no feminino: As mulheres portuguesas e a Guerra Colonial. Porto: Edições Afrontamento, 2007.

ANTILLI, Maria Aparecida. João Guimarães Rosa e José Luandino Vieira: a voz e a letra. In: CHAVES, Rita; MACÊDO, Tania; VECCHIA, Rejane (org.). A kinda e a misanga. Encontros brasileiros com a literatura angolana. São Paulo: Cultura Acadêmica; Luanda: Editorial Nzila, 2007.

SANTOS, Boaventura de Sousa. A gramática do tempo: para uma nova cultura política. São Paulo: Cortez, 2006.

VALENTE, André. Neologismos literários em romance de Mia Couto. Língua portuguesa e identidade: marcas culturais. Rio de Janeiro: Caetés, 2007

VIEIRA, José Luandino. Luuanda. São Paulo: Companhia das Letras, 2006 